\title{
The Influence of Inelastic Pre-straining on Fracture Toughness Behaviour of Type 316H Stainless Steel
}

\author{
Ali Mehmanparast ${ }^{1 *}$ and Catrin M. Davies ${ }^{2}$ \\ ${ }^{1}$ Offshore Renewable Energy Centre, School of Energy, Environment and Agrifood, \\ Cranfield University, Cranfield, Bedfordshire MK43 0AL, UK. \\ ${ }^{2}$ Mechanical Engineering Department, Imperial College London, South Kensington Campus, \\ London SW7 2AZ, UK. \\ *Corresponding author: a.mehmanparast@cranfield.ac.uk
}

\begin{abstract}
The effects of inelastic deformation, in the form of plastic and creep pre-strain, on the fracture toughness behaviour of Type $316 \mathrm{H}$ stainless steel have been investigated in this study. Material pre-conditioning effects on the strain distribution fields ahead of the crack tip have been investigated using digital image correlation. Fracture toughness tests have been performed on compact tension specimens made of the as-received, plastic pre-strained and creep pre-strained materials. The influences of specimen side grooves and pre-cracking type on the fracture toughness behaviour of $316 \mathrm{H}$ stainless steel have also been examined. The test results have shown that the fracture toughness values decrease by increasing the percentage of inelastic strain introduced into the material. Moreover, the generated R-curves and the subsequent fracture toughness values have been found sensitive to the specimen side groove. Finally, it has been observed that local creep damage has more severe impact on the fracture toughness of the material compared to global creep deformation.
\end{abstract}

Keywords: fracture toughness, digital image correlation, plastic pre-strain, creep pre-strain

\author{
Nomenclature \\ a Crack length \\ $a_{0} \quad$ Initial crack length \\ $a_{f} \quad$ Final crack length \\ $\Delta a \quad$ Increment of crack growth \\ $\Delta a_{\max } \quad$ Maximum allowable crack extension in fracture toughness tests \\ $B \quad$ Specimen thickness \\ $B_{e} \quad$ Effective thickness \\ $B_{n} \quad$ Specimen net thickness between the side grooves \\ C Unloading compliance \\ E $\quad$ Young's Modulus \\ $E_{M} \quad$ Effective Young's modulus in fracture toughness data analysis \\ $J_{0, k} \quad$ Fracture resistance at the $k$ th interval \\ $J_{0.2 / B L} \quad$ Fracture resistance at $0.2 \mathrm{~mm}$ of stable crack extension
}




$\begin{array}{cl}J_{\text {max }} & \text { Maximum allowable } J \text { in fracture toughness tests } \\ J_{I C} & \text { Critical value of } J \text { for fracture under Mode I loading conditions } \\ U_{k} & \begin{array}{l}\text { Area under the force } v s . \text { displacement curve up to the line of constant displacement } \\ \text { at the } k \text { th interval }\end{array} \\ W & \text { Specimen width } \\ \eta & \text { Factor relating } J \text { to load and displacement measurements } \\ \varepsilon_{c} & \text { Creep strain } \\ \sigma_{0.2} & 0.2 \% \text { proof stress } \\ \sigma_{0.5} & 0.5 \% \text { proof stress } \\ \text { AGR } & \text { Advanced gas cooled rector } \\ \text { AR } & \text { As-received material state } \\ \text { CCG } & \text { Creep crack growth } \\ \text { DIC } & \text { Digital image correlation } \\ \text { EDM } & \text { Electrical discharge machining } \\ \text { GCD } & \text { Globally creep deformed material } \\ \text { HAZ } & \text { Heat affected zone } \\ \text { LCD } & \text { Local creep damage material state } \\ \text { LLD } & \text { Load line displacement } \\ \text { PC } & \text { Pre-compressed material state } \\ \text { SEM } & \text { Scanning electron microscopy } \\ \text { SS } & \text { Stainless steel } \\ \text { TC } & \text { Thermocouple } \\ \text { UTS } & \text { Ultimate tensile strength } \\ & \\ & \end{array}$

\section{Introduction}

Material pre-conditioning can be introduced into engineering components in the form of plastic pre-strain during the fabrication process or in the form of creep pre-strain during operation at elevated temperatures. Type $316 \mathrm{H}$ stainless steel (SS) is widely used in the UK's power industry, for example steam headers in advanced gas cooled rectors (AGRs). Many of these components were previously operating for a few decades at high temperatures (i.e. at around $550{ }^{\circ} \mathrm{C}$ ) in which creep deformation and crack growth is the dominant failure mechanism. However, in order to extend the lifetime of these high temperature components their operating temperatures were reduced to limit the accumulation of in-service creep deformation and damage. In order to assess the structural integrity of these AGR power plant components it is important to consider the influence of prior inelastic (i.e. plastic and creep) pre-straining on the subsequent mechanical response, fracture and crack growth behaviour of the material. The influence of plastic pre-straining, introduced in the form of uniform precompression to $8 \%$ plastic strain at room temperature, on the tensile, fracture toughness and creep deformation and crack growth behaviour of Type $316 \mathrm{H}$ SS has been extensively 
examined in previous work by authors [1-3]. The experimental results in [1-5] have shown that plastic pre-straining leads to an increase in the yield stress, reduction in tensile strain at failure and also a decrease in fracture toughness of 316 steel. Literature studies on other engineering materials have shown that similar changes in mechanical response and fracture behaviour of material are generally observed when test specimens were subjected to tensile or compressive plastic pre-staining e.g. see [6-11]. The results obtained from these studies have shown that the fracture toughness value decreases as the percentage of tensile or compressive plastic pre-stain increases in the material e.g. [12]. The influence of creep pre-straining, introduced into round bar $316 \mathrm{H} \mathrm{SS}$ specimens by interrupting uniaxial creep tests at $550{ }^{\circ} \mathrm{C}$, on subsequent room temperature tensile behaviour of the material has been investigated in [13]. The experimental results obtained from crept specimens in [13-15] have shown that creep deformation (i.e. development of uniform creep pre-strain in uniaxial creep deformation tests) increases the yield stress and reduces the tensile strain at failure of 316 material.

The experimental results available in the literature suggest that plastic and creep prestraining have similar effects on the tensile and fracture behaviour of a given metallic material. The previous work by authors on plastically pre-compressed $316 \mathrm{H} \mathrm{SS}$ has confirmed that the fracture toughness of this material decreases by introducing uniform plastic pre-strain [3]. Although the global response of the as-received (AR) and precompressed (PC) material states was studied under fracture loading conditions in [3], further research is required to better understand the local response of the AR and PC material states. Therefore in the present study the authors have investigated the material plastic pre-straining effects on the strain distribution fields ahead of the notch tip using digital image correction (DIC) measurement technique to better understand the global fracture behaviour of the material in relation to local deformation. Moreover, although the influence of local creep damage (LCD) on fracture toughness of Type 316H SS was previously studies in [3] by performing tests on interrupted creep crack growth (CCG) specimens, further experimental work has been conducted in the present study to investigate the uniformly introduced global creep deformation (GCD) effects on the fracture toughness behaviour of Type 316H SS. The results presented in this paper fill the knowledge gap and provide a better understanding of how inelastic deformation, in the form of uniform plastic and creep pre-strain, influence the fracture toughness behaviour of the material.

\section{Material Pre-Straining and Specimen Preparation}

The specimens tested in this work were extracted from a service exposed steam header made of $316 \mathrm{H}$ SS which was provided by EDF Energy. Four blocks of material were extracted from the ex-service steam header, two of which were uniformly pre-compressed to $8 \%$ plastic strain at room temperature following the procedure detailed in [1-3]. Four standard compact tension, $\mathrm{C}(\mathrm{T})$, specimens of width $W=50 \mathrm{~mm}$ were machined from these blocks to prepare two AR specimens (i.e. from the uncompressed blocks) and two PC specimens (i.e. from the uniformly pre-compressed blocks). To investigate the crack tip sharpness effects on the local strain distribution fields during fracture toughness tests, for both material states considered in this study the starter crack in one specimen was introduced using an electrical discharge machining (EDM) notch of root radius $0.125 \mathrm{~mm}$ (denoted JIC-AR-EDM and JICPC-EDM) whereas the second specimen was pre-fatigue cracked (denoted JIC-AR-PF and JIC-PC-PF) to introduce a sufficiently sharp crack tip into the sample. All of these four specimens were manufactured plain sided (i.e. with no side grooves) to facilitate DIC measurements on the outer surface of the test specimens. 
In order to introduce global creep deformation into the material, a larger block was extracted from the steam header, squared off and uniformly pre-compressed to $8 \%$ plastic strain at room temperature. Due to the limited material available, the large PC block was welded to 316 extension plates to provide enough room for gripping purposes and pulling the sample in tension at high temperature to subsequently introduce creep strain into the material (see Figure 1). This was done in such a way that the PC material was located at the midlength of the large uniaxial specimen. In order to maximise the stress in the gauge region, where the PC material was located, the extension pieces were designed to have a larger cross sectional area, thus lower stress level for a given applied load (see Figure 1). As seen in Figure 1 the cross sectional area of the gauge region, made of PC material, was $26 \times 63 \mathrm{~mm}^{2}$. These dimensions were chosen to allow standard $\mathrm{C}(\mathrm{T})$ specimen of width $W=50 \mathrm{~mm}$ to be extracted subsequent to uniaxial creep testing by accounting for possible necking effects during the specimen load up and creep deformation.

Once the large uniaxial specimen was prepared, it was pulled in tension at $550{ }^{\circ} \mathrm{C}$ to introduce creep strain into the gauge region. To monitor the creep strain during the test, two capacitance gauges were attached to the sample at the mid-height (capacitance gauge 1) and lower part (capacitance gauge 2) of the gauge region as shown in Figure 1 and Figure 2. Furthermore, a large 3-zone furnace was used to increase and maintain the specimen temperature at $550{ }^{\circ} \mathrm{C}$ and the temperature variation across the specimen was monitored using 18 thermocouples (TC) spot welded to different parts of the sample, inside and outside the gauge region, on all four faces. The location of thermocouples attached to two faces of the GCD specimen has been schematically shown in Figure 1. The large sample was set up on an Instron machine with the maximum load carrying capacity of 2,500 kN (see Figure 3 ) and the uniaxial creep test was carried out under $300 \mathrm{MPa}$ applied stress at $550{ }^{\circ} \mathrm{C}$. Note that although the temperature was stabilised at $550{ }^{\circ} \mathrm{C}$ in the mid-height of the gauge region, some variations of around $\pm 5{ }^{\circ} \mathrm{C}$ (less than $1 \%$ of the test temperature) were recorded from thermocouples attached to different parts of the sample. Uniaxial creep test was conducted on the large specimen and eventually interrupted when the instantaneous creep strain rate of around double the minimum creep strain rate was observed in the tertiary creep region. The average creep strain, $\varepsilon_{c}$, variation against time is presented in Figure 4. As seen in this figure a uniform creep strain of around 5\% was introduced into the material located at the gauge region. Due to limited material available in the gauge region only a single standard size $\mathrm{C}(\mathrm{T})$ specimen of $W=50 \mathrm{~mm}$ was extracted from the mid-section of the crept material subsequent to test interruption. The $\mathrm{C}(\mathrm{T})$ specimen extracted from the globally creep deformed material, denoted JIC-GCD-SG, was side grooved by $10 \%$ of the total thickness at each side and precracked using an EDM notch of root radius $0.125 \mathrm{~mm}$. Note that the GCD material state in this study is referred to prior plastic pre-straining followed by creep pre-straining, hence inelastic pre-straining which was introduced into the material from which JIC-GCD-SG specimen is extracted.

The mechanical properties of the AR, PC and GCD materials have been previously characterised and reported in $[2,13]$. A summary of the tensile properties of these materials at room temperature has been shown in Table 1. As seen in this table, although the elastic Young's modulus, $E$, value for the $\mathrm{PC}$ material is $6 \%$ higher than the AR material and the GCD material $E$ is $9 \%$ lower than the PC material, within the inherent experimental scatter similar $E$ values have been found for the AR, PC and GCD material states. Also seen in Table 1 is that the ultimate tensile strength (UTS) values in the AR and PC materials are almost the same, however the UTS in GCD material is around 10\% lower than the AR and PC material states. As explained in [2] and shown in Table 1, although the yield stress (taken as $0.2 \%$ proof stress, $\sigma_{0.2}$ ) of the PC material has been found to fall slightly below that of measured in 
the AR material, hardening effects start to appear in the PC material at plastic strain levels of greater than $0.2 \%$. Finally seen in Table 1 is that the highest and the lowest $0.5 \%$ proof stress, $\sigma_{0.5}$, values have been found in the GCD and AR material states with the PC value falling in between.

All specimens made of inelastic (plastic and creep) pre-strained material tested in this work had the loading axis parallel to the compressive/tensile pre-straining direction. The specimen dimensions for all $\mathrm{C}(\mathrm{T})$ samples are summarised in Table 2. As seen in this table all samples had the total thickness of $B=25 \mathrm{~mm}$ and the initial normalised crack length, $a_{0} / W$, of around 0.5 which is within the valid range specified in standard fracture toughness test methods. Also included in this table are the initial and final crack lengths, and total crack extension estimates made using the unloading compliance data at the end of the tests on $\mathrm{C}(\mathrm{T})$ specimens. All samples were tested under fracture toughness loading conditions (i.e. sequences of loading and unloading) at room temperature.

\section{Fracture Toughness Testing and Analysis}

The standard test methods which are commonly used to perform and analyse fracture toughness tests on metallic materials are ASTM E1820 [16] and ESIS P2-92 [17]. The standard test method that has been followed in this work to conduct fracture toughness experiments and analyse the obtained test results is ESIS P2-92 [17]. Having known that $316 \mathrm{H} \mathrm{SS}$ is a ductile material, a summary of fracture toughness testing and analysis procedure to quantify $J_{I C}$ fracture parameter for ductile materials with stable crack extension is described below.

\subsection{Generation of the R-Curve}

In a fracture toughness test, the variation of $J$ fracture mechanics parameter can be correlated with the crack extension $\Delta a$. The " $J v s$. $\Delta a$ " correlation is often referred to as the R-curve (i.e. resistance curve). In order to estimate the crack extension in a fracture mechanics test performed using the single specimen approach, where the specimen is frequently loaded and unloaded until crack extension occurs, the instantaneous normalised crack length, $a / W$, can be approximated using the unloading compliance data by

$$
a / W=\left(\begin{array}{l}
1.000196-4.06319 \mu+11.242 \mu^{2} \\
-106.043 \mu^{3}+464.335 \mu^{4}-650.677 \mu^{5}
\end{array}\right)
$$

where

$$
\mu=\frac{1}{\sqrt{B_{e} E_{M} C}+1}
$$

In Eqn (2) $E_{M}$ is the effective Young's modulus which can be calculated using the equation given in [17], $C$ is the elastic unloading compliance and $B_{e}$ is the effective thickness which can be calculated using

$$
B_{e}=B-\left(B-B_{n}\right)^{2} / B
$$

where $B$ is the total thickness and $B_{n}$ is the net thickness between the side grooves. The fracture resistance at the $k^{\text {th }}$ interval, $J_{0, k}$, can be calculated by

$$
J_{0, k}=\frac{\eta U_{k}}{B_{n}\left(W-a_{0}\right)}
$$


where $W$ is the specimen's width, $a_{0}$ is the initial crack length, $U_{k}$ is the area under the "force $v s$. displacement" curve up to the line of constant displacement at the $k$ th interval and $\eta$ is a geometry dependent parameter solutions of which can be found in [18].

\subsection{Quantification of Fracture Toughness}

In order to identify the valid data points for a fracture toughness data analysis, exclusion lines must be plotted by calculating the slope of the blunting line using the equations given in the ESIS P2-92 standard [17] and constructing two parallel lines with $\Delta a_{\max }$ and $0.10 \mathrm{~mm}$ offsets, where $\Delta a_{\max }$ can be calculated using

$$
\Delta a_{\max }=0.10\left(W-a_{0}\right)
$$

The data points falling outside the exclusion lines are considered invalid and not included in the analysis.

The $J_{0.2 / B L}$ fracture toughness parameter can be quantified by finding the intersection point between the line of best fit to the valid data points on the R-curve and the line parallel to the blunting line with $0.2 \mathrm{~mm}$ offset. $J_{0.2 / B L}$ is considered valid if the following criteria are satisfied,

$$
\begin{gathered}
J_{0.2 / B L}<J_{\max } \\
\text { and } \\
(d J / d a)_{B L}>2(d J / d a)_{0.2 / B L}
\end{gathered}
$$

where $(d J / d a)_{B L}$ is the slope of the blunting line, $(d J / d a)_{0.2 / B L}$ is the slope of the best fit curve at $J_{0.2 / B L}$, and $J_{\max }$ can be calculated using

$$
J_{\max }=\operatorname{Min}\left\{\left(W-a_{0}\right)\left(\sigma_{0.2}+\sigma_{U T S}\right) / 40 ; B\left(\sigma_{0.2}+\sigma_{U T S}\right) / 40\right\}
$$

\section{Digital Image Correlation Measurements}

An experimental technique which has been widely used by other researchers to measure macro and micro scale true strain distribution fields in fracture specimens is the DIC measurement (e.g. [19-21]). For example, combined experimental-numerical methods have been proposed in [20] and [21] to use the DIC measurements and finite element modelling to quantify stress intensity factor and $J$-integral in fatigue crack growth and fracture toughness tests, respectively. Furthermore, DIC measurements have been used in [22] and [23] to measure micro scale surface damage in low cycle and high cycle fatigue tests on a stainless steel material, respectively. A combined DIC and optical microscopy technique has been employed in [24] to determine surface deformation at high magnifications and study the local properties of engineering materials. A similar technique has been employed in $[25,26]$ to perform DIC measurements in conjunction with scanning electron microscopy (SEM) to capture in-plane strain variation on a surface of a metallic material. In addition, high precision DIC measurements have enabled researchers to quantify mechanical properties of small heat affected zone (HAZ) regions in welded joints (e.g. see [27]). The results from the DIC measurements available in the literature show that digital image correlation technique provides accurate macro and micro strain maps on the outer surface of cracked and uncracked geometries. Hence, in this study a high resolution 3D DIC system was employed to measure the strain fields around the crack tip in fracture toughness tests on plain sided $\mathrm{C}(\mathrm{T})$ specimens made of the AR and PC materials. The DIC gauge measures displacement by comparing the specimen surface pattern as the specimen is loaded and deforms. This allows the gauge software to derive the change in displacement between two targets, which the software tracks on the specimen surface. In order to provide a suitable pattern on the plain sided fracture 
toughness specimens for the video gauge to track, the outer surface of specimens was lightly spray painted with a black and white speckle pattern. DIC images were captured during the tests and analysed post-testing to measure the strain distribution around the crack tip at different stages of the fracture toughness tests.

\section{Fracture Toughness Test Results}

\subsection{Load vs. Load Line Displacement Data from Fracture Toughness Tests}

Fracture toughness tests were carried out on four plain sided $\mathrm{C}(\mathrm{T})$ specimens (JIC-AREDM, JIC-AR-PF, JIC-PC-EDM and JIC-PC-PF) by performing sequences of loading and unloading on each specimen. These tests were conducted under machine displacement controlled mode with the loading/unloading rate of $0.02 \mathrm{~mm} / \mathrm{sec}, 60 \mathrm{sec}$ hold time at the peak loads, machine displacement increment of $0.2 \mathrm{~mm}$ for load/unload and unloading percentage of $20 \%$ from each peak load. DIC images were captured during the hold time at each peak load and were analysed subsequent to test completion. The load and load line displacement (LLD), measured using a clip gauge accommodated on the knife edges machined at the crack mouth of the specimens, were continuously measured during the tests and are presented in Figure 5. Also included in Figure 5 are the "load vs. LLD" data from the test on the side grooved globally creep deformed GCD specimen (JIC-GCD-SG). In Figure 5 and following figures the data points/trends for the AR, PC and GCD material states are shown in red, blue and green symbols/lines, respectively.

Some small discrepancy can be observed in the "load vs. LLD" trends obtained from the EDM and pre-fatigue cracked plain sided specimens in both $\mathrm{AR}$ and $\mathrm{PC}$ materials. Comparing the data trends in Figure 5 it can be seen that in the case of PC plain sided specimens a larger load was required for EDM pre-cracked specimen compared to the prefatigue cracked sample, to reach a given value of LLD. However, for the AR material the load required to obtain a given value of LLD was slightly higher in the pre-fatigue cracked specimen compared to the EDM pre-notched sample. It can be seen in Figure 5 that although the tests on the AR specimens didn't reach the maximum load $P_{\max }$ value, the decreasing load over LLD rates in these samples indicate that the $P_{\max }$ value in plain sided AR specimens is significantly lower than those of obtained from the PC specimens as a result of material hardening effects. This observation on plain sided $\mathrm{C}(\mathrm{T})$ specimens is consistent which that of reported in [3] for the side grooved AR and PC C(T) specimens.

\subsection{Fracture Toughness Results from Plain Sided AR and PC Specimens}

DIC images were captured during the hold time at each peak load to measure the strain distribution ahead of the crack tip at different stages of the fracture toughness tests. The strain distribution maps measured using the DIC technique at the outer surface of the plain sided JIC-AR-EDM, JIC-AR-PF, JIC-PC-EDM and JIC-PC-PF specimens are presented in Figure 6, Figure 7, Figure 8 and Figure 9, respectively. Also included in these figures are the "load $v s$. LLD" data and the R-curve fracture toughness data analysis for each of the test specimens examined. As seen in these figures, all peak loads have been numbered and the corresponding strain distribution maps are presented in Figure 6-Figure 9. For comparison purposes, the same strain scales of minimum $0 \%$ (blue contours) and maximum 5\% (red contours) have been used to present the DIC strain measurement results obtained from different specimens. Note that the red contour in DIC images is associated with strain values of $5 \%$ or higher. As seen in these figures, the DIC measurements have shown that for each of the specimens examined, the size of the strain field ahead of the notch tip has continuously increased by 
increasing the LLD, as expected, and the strain maps are symmetric with respect to the specimen symmetry line. It can be seen in Figure 6-Figure 9 that for a given value of applied load, the true strain fields ahead of the crack tip in the PC material are much smaller than those observed in the AR material. Also seen in Figure 6-Figure 9 is that for a given value of LLD, the crack tip strain fields in the AR material are larger than the PC material up to the point that the load reaches the maximum value, $P_{\max }$. Once the maximum load is attained in the fracture toughness tests on the PC material, the strain fields ahead of the crack tip get larger in the PC material compared to the AR. Interestingly, the change in the plastic zone sizes ahead of the crack tip which occurs at $P_{\max }$ coincides with the point at which $0.2 \mathrm{~mm}$ crack extension $\left(J_{0.2 / B L}\right)$ is observed in the R-curves for the PC specimens. Finally seen in these figures is that for a given value of LLD, greater strain values are observed at the back of the $\mathrm{C}(\mathrm{T})$ specimens made of the AR material compared to the PC material, indicating larger bending and more severe crack tip blunting in the AR specimens.

The R-curves for JIC-AR-EDM and JIC-AR-PF specimens presented in Figure 6 and Figure 7 show that " $J v s$. $\Delta a$ " data points obtained from the plain sided AR specimens fall upon or close to the blunting line with no evidence of deviation from linearity, whereas " $J v s$. $\Delta a$ " data for PC specimens in Figure 8 and Figure 9 exhibit non-linear trends from the beginning of the tests. This implies that the fracture behaviour of the plain sided AR specimens was mainly controlled by crack blunting (i.e. plastic deformation) with no evidence of significant crack extension (i.e. see small values of crack extension estimates for AR specimens in Table 2). This observation is consistent with relatively larger strain fields measured at the back of the AR specimens, compared to the PC material, presented in Figure 6-Figure 9. The plain sided PC specimens seem to have experienced minor blunting at the crack tip and relatively continuous crack extension from the early stages of the tests. This can be due to the formation of voids/damage in the material during the plastic pre-compression process and also lower tensile strain at failure in the pre-strained material as previously reported and discussed in [28]. The fracture toughness test results obtained from the plain sided AR and PC C(T) specimens are summarised in Table 3. As seen in this table due to the limited amount of crack extension in plain sided AR specimens, the fracture toughness values could not be determined for these two tests on JIC-AR-EDM and JIC-AR-PF samples. It can be seen in Table 3 that the fracture toughness $J_{0.2 / B L}$ value in the pre-fatigue cracked PC specimen is around $32 \%$ lower than that of obtained from the EDM pre-cracked PC sample.

Comparing the DIC measurements in Figure 6 and Figure 7 it can be seen that for a given peak load number, hence for a given value of LLD, the local strains at the crack tip in the AR material are relatively larger in the pre-fatigue cracked specimen compared to the specimen with an EDM starter crack. Moreover, the size of the red contours associated with the strain values of $5 \%$ or higher is greater in the pre-fatigue cracked AR specimen compared to the one with an EDM starter crack. Similar observation has been made in the strain distribution fields at different peak loads for pre-fatigue cracked and EDM pre-cracked PC specimens in Figure 8 and Figure 9. The ratio of the red contour size, associated with 5\% or higher strain values, in the pre-fatigue cracked specimen, $r_{5 \%-P F}$, to the EDM pre-cracked specimen, $r_{5 \%-E D M}$, has been calculated using the DIC measurements on the AR and PC materials and the results are summarised in Table 4. This ratio has been calculated for the peak loads of between 6 and 17 where strain values of $5 \%$ or larger where observed in all specimens. As seen in this table, for both the AR and PC materials the $r_{5 \%-P F} / r_{5 \%-E D M}$ ratio generally shows a decreasing trend as the LLD increases in the fracture toughness tests. It is worth noting that this ratio has been found to be above unity at all time (including towards the end of the tests) implying that the local strains and subsequently the size of the large strain fields ahead of the crack tip are always higher in the pre-fatigue cracked specimens compared to those with an EDM starter 
crack. This explains why $J_{0.2 / B L}$ value in the pre-fatigue cracked PC specimen is lower than the EDM pre-cracked specimen.

\subsection{Fracture Toughness Results from GCD Specimen}

The R-curve data obtained from the fracture toughness test on the side grooved GCD specimen (JIC-GCD-SG) have been analysed following the instructions given in Section 3 and the results are shown in Figure 10 and summarised in Table 3. Room temperature tensile properties of the GCD material, taken from [13] and summarised in Table 1, were employed in the fracture toughness data analysis. Note that no DIC measurement was conducted on this specimen due to the lack of plain surface at the outer surface of the sample. As mentioned earlier the GCD specimen was subjected to prior plastic pre-strain before introduction of creep pre-strain, hence contained inelastic deformation. Comparison of the fracture toughness tests results for the PC and GCD materials given in Table 3 shows that for the side grooved GCD material (JIC-GCD-SG) the fracture toughness parameter $J_{0.2 / B L}$ is lower than those of obtained from plain sided PC specimens. This implies that inelastic deformation, in the form of combined plastic and creep pre-straining, decreases the fracture toughness of the material.

\section{Discussion}

The fracture toughness tests on AR and PC materials in the current study were performed on plain sided specimens to facilitate DIC measurements. In order to examine the influence of specimen side grooves on the fracture toughness of the AR and PC specimens, the R-curves from the tests conducted on plain sided specimens have been compared with those of available on the side grooved AR and PC specimens in [3] and the results are shown in Figure 11 and Figure 12, receptively. Note that in these two figures the data points corresponding to plain sided and side grooved specimens are shown in open and solid symbols, respectively. It can be seen in Figure 11 and Figure 12 that for a given value of crack extension, the corresponding value of $J$ fracture mechanics parameter is significantly lower in the side grooved AR and PC specimens compared to the plain sided samples. This implies that there is less energy required to initiate the crack when the specimen is side grooved. Comparison of the fracture toughness values in the pre-fatigue cracked plain sided PC specimen (see JIC-PC-PF in Table 3) with those of reported for the side grooved and prefatigue cracked PC specimens (JIC-PC-SG1 and JIC-PC-SG2) in [3] reveals that introducing side grooves in a PC specimen reduces the $J_{0.2 / B L}$ fracture toughness value from 0.28 to $0.21 \mathrm{MPam}$. This means that the generated R-curves and subsequently the quantified value of $J_{0.2 / B L}$ fracture toughness parameter are sensitive to the specimen side grooves.

In order to further investigate the influence of inelastic pre-straining on the fracture behaviour of $316 \mathrm{H} \mathrm{SS}$, the R-curve from the fracture toughness test performed on the GCD specimen has been compared with those of obtained from side grooved $\mathrm{C}(\mathrm{T})$ specimens made of AR and PC materials [3] and the results are shown in Figure 13. Also included in this figure are the R-curves from fracture toughness tests on interrupted CCG specimens which were made of PC material, denoted JIC-LCD1 and JIC-LCD2, taken from [3]. In these two specimens the creep damage was confined to a small region ahead of the crack tip, by interrupting CCG tests, as opposed to the GCD specimen in which creep strain was globallyuniformly introduced into the material. Note that in both LCD and GCD specimens the material was previously pre-compressed to $8 \%$ plastic strain at room temperature. Comparing the R-curves obtained from the side grooved $\mathrm{C}(\mathrm{T})$ specimens made of different material states in Figure 13 it can be seen that for a given value of crack extension, the order of variation in fracture mechanics parameter $J$ from small to large is LCD, GCD, PC and AR material. The difference between the R-curves for the GCD, PC and AR materials is more 
pronounced at larger values of crack extension (i.e. $\Delta a>0.6$ ), though at smaller values of $\Delta a$, the resistance curves fall close to each other. It can be seen in Table 3 and [3] that $J_{0.2 / B L}$ values in $\mathrm{LCD}, \mathrm{GCD}, \mathrm{PC}$ and $\mathrm{AR}$ materials are 0.03, 0.16, 0.21 and $0.25 \mathrm{MPam}$. This variation in fracture toughness values for different material states is consistent with the Rcurve trends observed in Figure 13 for larger values of $\Delta a$.

As explained in [3], the small values of fracture toughness in LCD specimens may be associated with crack discontinuities which occur along the main crack path as a result of intergranular creep crack growth process. This may explain why the LCD material state has been found to have more severe impact on fracture toughness reduction of the material compared to the GCD condition. Furthermore, the R-curves presented for different material states in Figure 13 indicate that uniform pre-straining in the form of plastic (in compression) or creep (in tension) deformation reduce the fracture toughness of the material. Also seen in this figure is that the fracture toughness value continuously decreases as the inelastic (i.e. combined plastic and creep) pre-straining level increases.

The results and observations presented in the current study are based on experiments. A numerical study will be performed in future work to predict the effects of different extent of inelastic pre-straining on the subsequent fracture toughness behaviour of the material.

\section{Conclusions}

The influence of inelastic deformation on fracture toughness behaviour of Type $316 \mathrm{H}$ stainless steel has been investigated in this study. Experiments have been performed on specimens made of the as-received (AR), 8\% pre-compressed (PC) and globally creep deformed (GCD) material states. The DIC measurements on the outer surface of the notched specimens have shown that under a given applied load the true strain fields ahead of the crack tip in PC material are much smaller than those of observed in the AR material. The results have also shown that for a given value of load line displacement, the crack tip strain fields in the AR material are larger than the PC material at lower load levels. However, when the maximum load is attained in PC specimens, larger crack tip strain fields are observed in the PC material compared to the AR material and crack initiation becomes evident in the Rcurves generated for the PC specimens. The experimental results have shown that the local strains are higher, therefore the fracture toughness $J_{0.2 / B L}$ value is lower, in the pre-fatigue cracked PC specimen compared to the EDM pre-cracked PC sample. The fracture toughness results from plain sided and side grooved AR and PC specimens have shown that the generated R-curves and subsequently the quantified value of $J_{0.2 / B L}$ fracture toughness parameter are sensitive to the specimen side grooves. Comparison of the fracture toughness data obtained from different materials has shown that the order of variation in fracture toughness $J_{0.2 / B L}$ values from small to large is local creep damage (LCD), GCD, PC and AR material state with the local creep damage having a more severe impact on the fracture toughness of the material compared to other pre-conditioning states. Knowing that LCD and GCD specimens were made of PC material, this implies that inelastic deformation, in the form of combined plastic and creep pre-straining, decreases the fracture toughness of the material.

\section{Acknowledgements}

The authors would like to thank EDF Energy for providing material for testing. This work has been supported by the UK High Temperature Centre (HTC). 


\section{References}

[1] Mehmanparast A, Davies CM, Dean DW, Nikbin K. Material pre-conditioning effects on the creep behaviour of $316 \mathrm{H}$ stainless steel. International journal of pressure vessels and piping. 2013;108-109:88-93.

[2] Mehmanparast A, Davies CM, Dean DW, Nikbin KM. The Influence of Pre-Compression on the Creep Deformation and Failure Behaviour of Type 316H Stainless Steel. Engineering Fracture Mechanics. 2013;110:52-67.

[3] Mehmanparast A, Davies CM, Dean DW, Nikbin KM. Plastic pre-compression and creep damage effects on the fracture toughness behaviour of Type $316 \mathrm{H}$ stainless steel. Engineering Fracture Mechanics. 2014;131:26-37.

[4] Liaw PK, Landes JD. Influence of prestrain history on fracture toughness properties of steels. Metallurgical and materials transactions A, Physical metallurgy and materials science. 1986;17:473-89.

[5] Acar M, Gungor S, Bouchard PJ, Fitzpatrick ME. Effect of Prior Cold Work on the Mechanical Properties of Weldments. In: Proulx T, editor. Experimental and Applied Mechanics, Volume 6: Springer New York; 2011. p. 817-26.

[6] Sivaprasad S, Tarafder S, Ranganath VR, Ray KK. Effect of prestrain on fracture toughness of HSLA steels. Materials Science and Engineering: A. 2000;284:195-201.

[7] Fukuda N, Hagiwara N, Masuda T. Effect of Prestrain on Tensile and Fracture Toughness Properties of Line Pipes. Journal of Offshore Mechanics and Arctic Engineering. 2005; 127:263-8.

[8] Hagiwara N, Oguchi N, Masuda T. Effects of Prestrain on Fracture Toughness and Fatigue-Crack Growth of Line Pipe Steels. Journal of Pressure Vessel Technology. 2001;123:355-61.

[9] Minami F, Arimochi K. Evaluation of Prestraining and Dynamic Loading Effects on the Fracture Toughness of Structural Steels by the Local Approach. Journal of Pressure Vessel Technology. 2001;123:362-72.

[10] Mills WJ. Fracture toughness of type 304 and 316 stainless steels and their welds. International Materials Reviews. 1997;42:45-82.

[11] Ainsworth RA. An assessment of the effects of prestrain on upper shelf fracture toughness. The Journal of Strain Analysis for Engineering Design. 1986;21:219-24.

[12] Mehmanparast A, Davies CM, Dean DW, Nikbin K. Effects of plastic pre-straining level on the creep deformation, crack initiation and growth behaviour of $316 \mathrm{H}$ stainless steel. International Journal of Pressure Vessels and Piping. 2016;141:1-10.

[13] Mehmanparast A, Davies CM, Dean DW, Nikbin KM. The Influence of Inelastic Damage on Tensile Deformation and Creep Crack Growth Behaviour of Type 316H Stainless Steel. ASME-PVP 14-18 July Paris-France: Proceedings of the International Conference on Pressure Vessels and Piping; 2013.

[14] Gan D. Tensile and fracture properties of type 316 stainless steel after creep. Metallurgical and Materials Transactions A. 1982;13:2155-63.

[15] Albertini C, Montagnani M. Strain-rate dependence of residual strength and ductility of AISI 316 stainless steel after creep, fatigue and irradiation. Res mechanica. 1990;30:361-75.

[16] ASTM. E 1820-09: Standard Test Method for Measurement of Fracture Toughness. Annual Book of ASTM Standards. 2009;03.01:1024-57.

[17] ESIS. P2-92: Procedure for Determining the Fracture Behaviour of Materials. European Structural Integrity Society Publication; 1992.

[18] Davies CM, Kourmpetis M, O'Dowd NP, Nikbin KM. Experimental Evaluation of the $J$ or $C^{*}$ Parameter for a Range of Cracked Geometries. Journal of ASTM International. 2006;3:1-20. 
[19] Savic V, Hector Jr LG, Fekete JR. Digital Image Correlation Study of Plastic Deformation and Fracture in Fully Martensitic Steels. Exp Mech. 2010;50:99-110.

[20] Hamam R, Hild F, Roux S. Stress Intensity Factor Gauging by Digital Image Correlation: Application in Cyclic Fatigue. Strain. 2007;43:181-92.

[21] Becker TH, Mostafavi M, Tait RB, Marrow TJ. An approach to calculate the J-integral by digital image correlation displacement field measurement. Fatigue \& Fracture of Engineering Materials \& Structures. 2012;35:971-84.

[22] El Bartali A, Aubin V, Degallaix S. Fatigue damage analysis in a duplex stainless steel by digital image correlation technique. Fatigue \& Fracture of Engineering Materials \& Structures. 2008;31:137-51.

[23] Poncelet M, Barbier G, Raka B, Courtin S, Desmorat R, Le-Roux JC, et al. Biaxial High Cycle Fatigue of a type 304L stainless steel: Cyclic strains and crack initiation detection by digital image correlation. European Journal of Mechanics - A/Solids. 2010;29:810-25.

[24] Sun Z, Lyons JS, McNeill SR. Measuring Microscopic Deformations with Digital Image Correlation. Optics and Lasers in Engineering. 1997;27:409-28.

[25] Lagattu F, Bridier F, Villechaise P, Brillaud J. In-plane strain measurements on a microscopic scale by coupling digital image correlation and an in situ SEM technique. Materials Characterization. 2006;56:10-8.

[26] Doumalin P, Bornert M. Micromechanical Applications of Digital Image Correlation Techniques. In: Jacquot P, Fournier J-M, editors. Interferometry in Speckle Light: Springer Berlin Heidelberg; 2000. p. 67-74.

[27] Molak RM, Paradowski K, Brynk T, Ciupinski L, Pakiela Z, Kurzydlowski KJ. Measurement of mechanical properties in a $316 \mathrm{~L}$ stainless steel welded joint. International Journal of Pressure Vessels and Piping. 2009;86:43-7.

[28] Mehmanparast A, Davies CM, Ardakani M, Nikbin KM. A Microstructural Study of Compressive Plastic Pre-Strain Effects on Creep Damage Behaviour of Type 316H Stainless Steel. ASME-PVP 17-21 July Baltimore-US: proceedings of the International Conference on Pressure Vessels and Piping; 2011. 


\section{Tables}

Table 1: Tensile properties of the AR, PC and GCD materials at room temperature

\begin{tabular}{|c|c|c|c|c|}
\hline Material State & $\begin{array}{c}E \\
(\mathrm{GPa})\end{array}$ & $\begin{array}{c}\sigma_{0.2} \\
(\mathrm{MPa})\end{array}$ & $\begin{array}{c}\sigma_{0.5} \\
(\mathrm{MPa})\end{array}$ & $\begin{array}{c}U T S \\
(\mathrm{MPa})\end{array}$ \\
\hline $\mathrm{AR}$ & 205 & 313 & 336 & 603 \\
\hline $8 \% \mathrm{PC}$ & 217 & 256 & 347 & 604 \\
\hline $\mathrm{GCD}$ & 198 & 459 & 463 & 544 \\
\hline
\end{tabular}

Table 2: Compact tension specimen dimensions

\begin{tabular}{|c|c|c|c|c|c|c|c|}
\hline Test ID & Pre-cracking type & $\begin{array}{c}W \\
(\mathrm{~mm})\end{array}$ & $\begin{array}{c}B \\
(\mathrm{~mm})\end{array}$ & $\begin{array}{c}B_{n} \\
(\mathrm{~mm})\end{array}$ & $\begin{array}{c}a_{0} \\
(\mathrm{~mm})\end{array}$ & $\begin{array}{c}a_{f} \\
(\mathrm{~mm})\end{array}$ & $\begin{array}{c}\Delta a \\
(\mathrm{~mm})\end{array}$ \\
\hline JIC-AR-EDM & EDM & 50.0 & 25.0 & 25.0 & 25.5 & 25.7 & 0.2 \\
\hline JIC-AR-PF & Pre-fatigue & 50.0 & 25.0 & 25.0 & 25.2 & 25.5 & 0.3 \\
\hline JIC-PC-EDM & EDM & 50.0 & 25.0 & 25.0 & 26.1 & 27.1 & 1.0 \\
\hline JIC-PC-PF & Pre-fatigue & 50.0 & 25.0 & 25.0 & 26.3 & 27.4 & 1.1 \\
\hline JIC-GCD-SG & EDM & 50.0 & 25.0 & 20.0 & 25.2 & 30.3 & 5.1 \\
\hline
\end{tabular}

Table 3: A summary of fracture toughness test results

\begin{tabular}{|c|c|c|c|c|c|}
\hline \multirow{2}{*}{ Test ID } & $\begin{array}{c}\Delta a_{\max } \\
(\mathrm{mm})\end{array}$ & $\begin{array}{c}J_{\max } \\
(\mathrm{MPam})\end{array}$ & Blunting line slope & $\begin{array}{c}J_{0.2 / B L} \\
(\mathrm{MPam})\end{array}$ & $2 d J / d \Delta a_{(0.2 / B L)}$ \\
\hline JIC-AR-EDM & 2.45 & 0.56 & \multirow{2}{*}{2.334} & - & - \\
\cline { 1 - 3 } JIC-AR-PF & 2.48 & 0.57 & & - & - \\
\hline JIC-PC-EDM & 2.39 & 0.51 & \multirow{2}{*}{2.333} & 0.41 & 2.16 \\
\cline { 1 - 3 } JIC-PC-PF & 2.37 & 0.51 & & 0.28 & 1.62 \\
\hline JIC-GCD-SG & 2.48 & 0.62 & 1.997 & 0.16 & 1.38 \\
\hline
\end{tabular}


Table 4: Comparison of the strain distributions ahead of the crack tip in specimens with prefatigue and EDM starter cracks

\begin{tabular}{|c|c|c|}
\hline \multirow{2}{*}{$\begin{array}{c}\text { Peak Load } \\
\text { Number }\end{array}$} & \multicolumn{2}{|c|}{$r_{5 \%-P F} / r_{5 \%-E D M}$} \\
\cline { 2 - 3 } & AR & PC \\
\hline 6 & 1.4 & 2.3 \\
\hline 7 & 1.4 & 2.0 \\
\hline 8 & 1.3 & 1.9 \\
\hline 9 & 1.5 & 1.9 \\
\hline 10 & 1.4 & 1.5 \\
\hline 11 & 1.2 & 1.5 \\
\hline 12 & 1.3 & 1.3 \\
\hline 13 & 1.3 & 1.4 \\
\hline 14 & 1.3 & 1.3 \\
\hline 15 & 1.2 & 1.4 \\
\hline 16 & 1.2 & 1.3 \\
\hline 17 & 1.3 & 1.3 \\
\hline
\end{tabular}




\section{Figures}

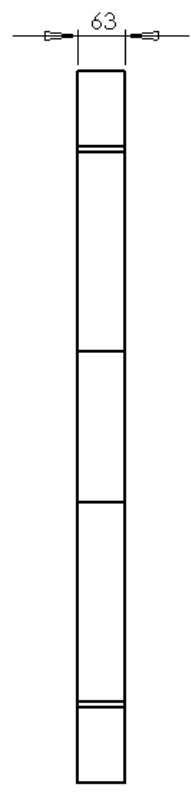

(a)

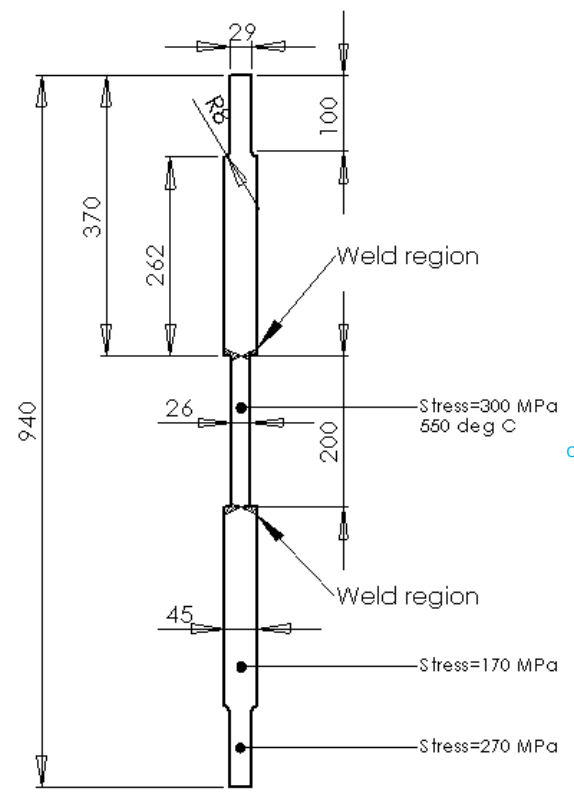

(b)

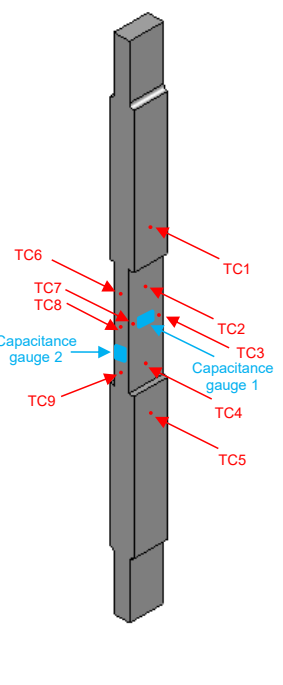

(c)

Figure 1: Global creep deformation specimen design (a) front view (b) side view (c) 3D view (all dimensions are in millimetres)

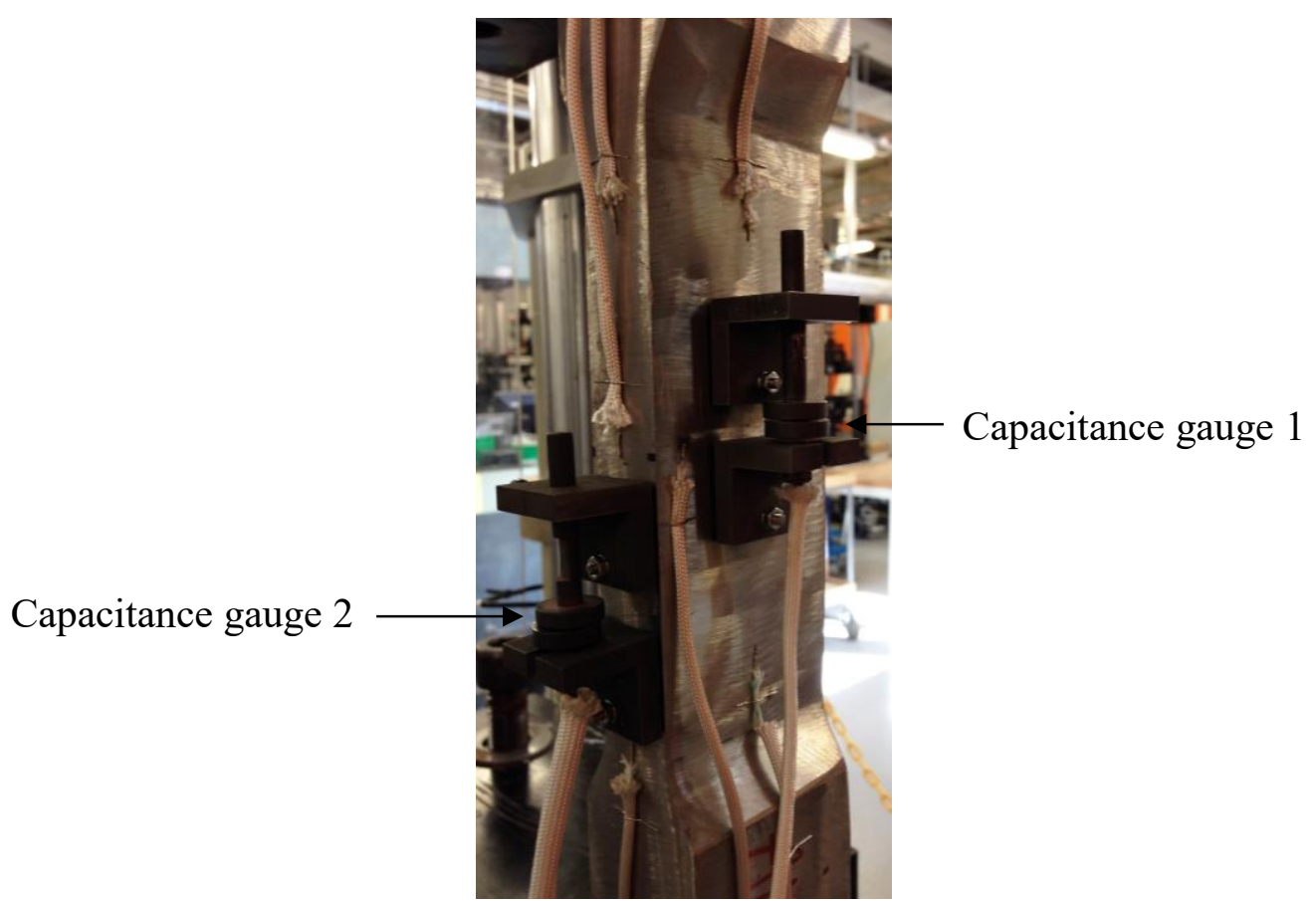

Figure 2: Creep strain monitoring on the global creep deformation specimen using two capacitance gauges 


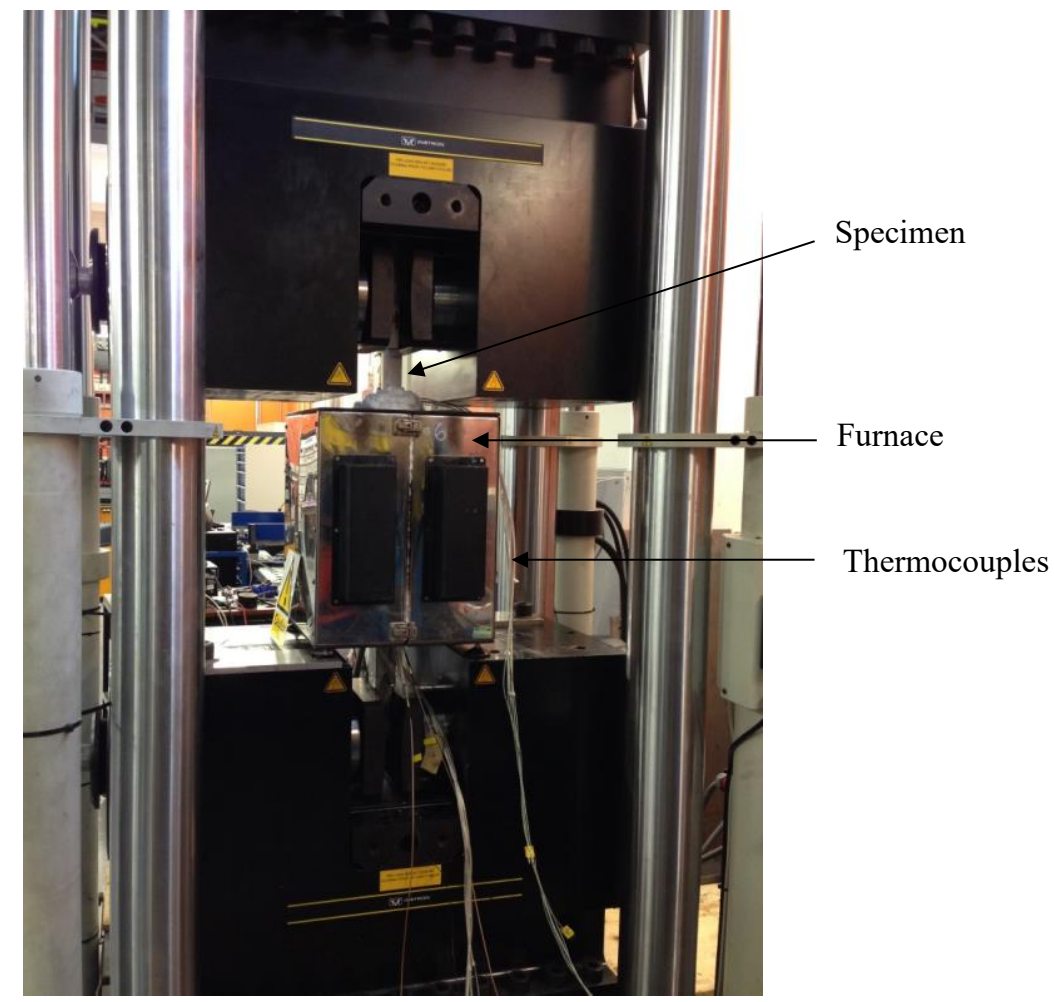

Figure 3: Global creep deformation test set up

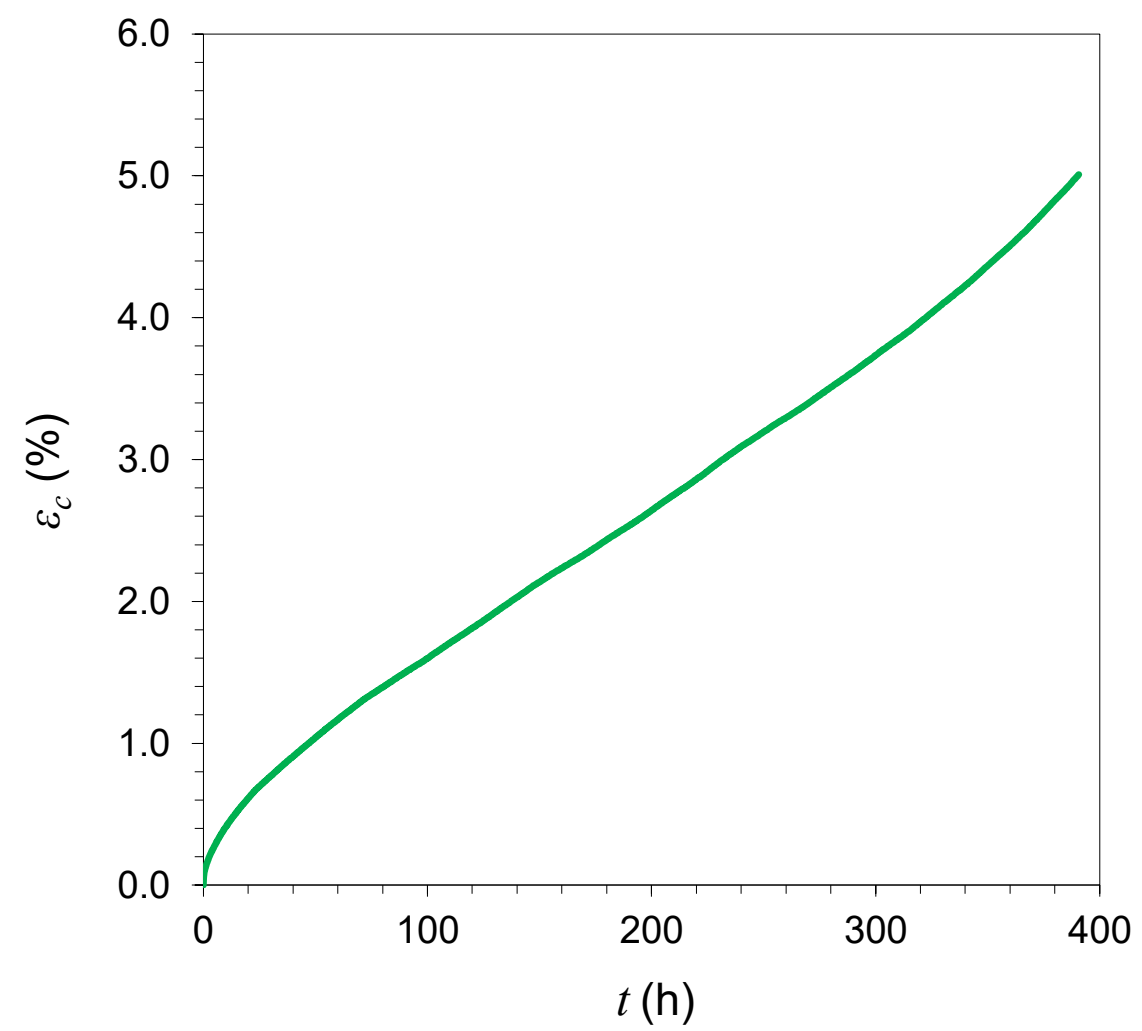

Figure 4: Development of creep strain $v s$. time in the interrupted uniaxial creep test 


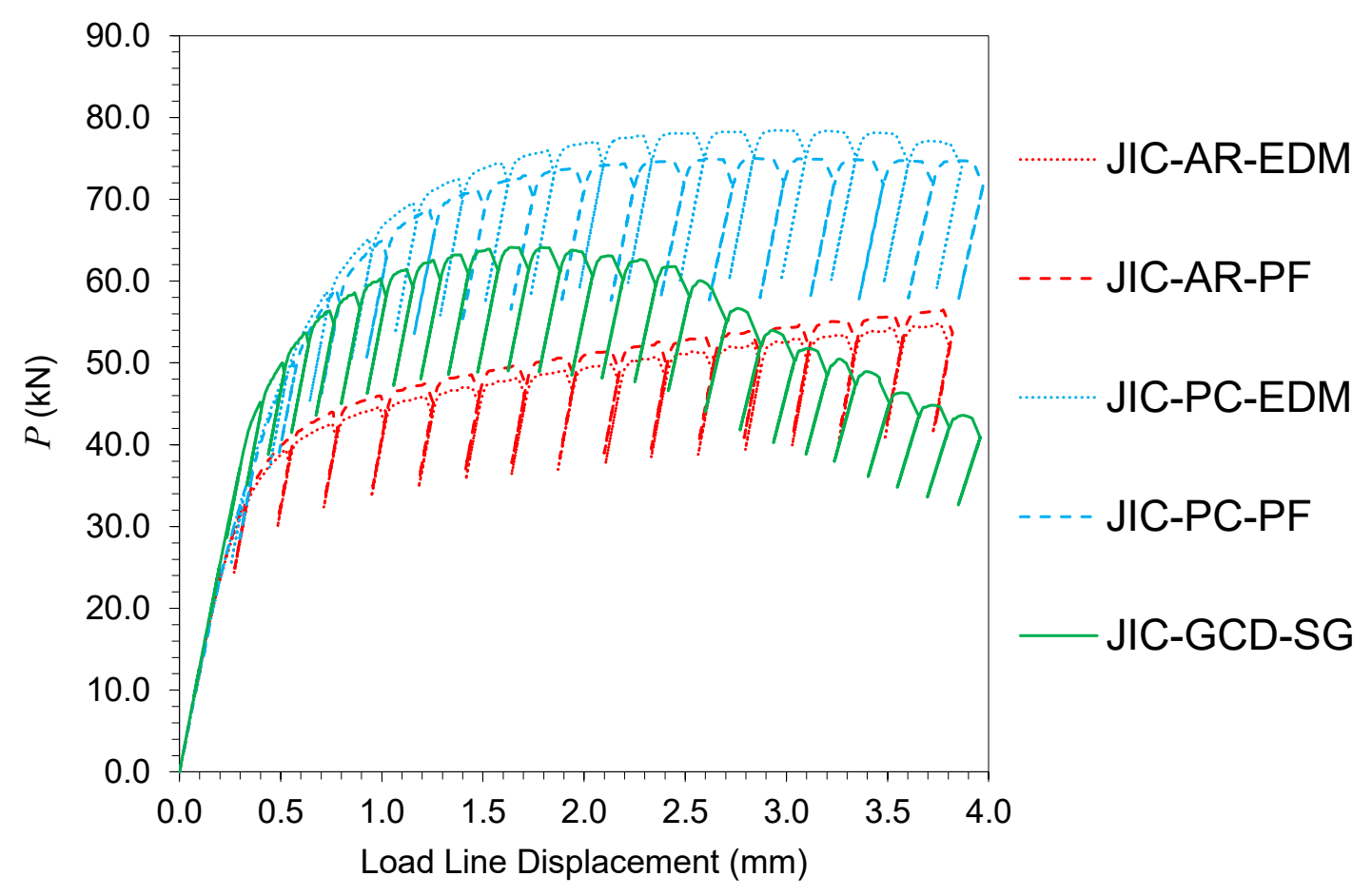

Figure 5: Load vs. LLD data from the fracture toughness tests performed on the AR, PC and GCD specimens 
(a)

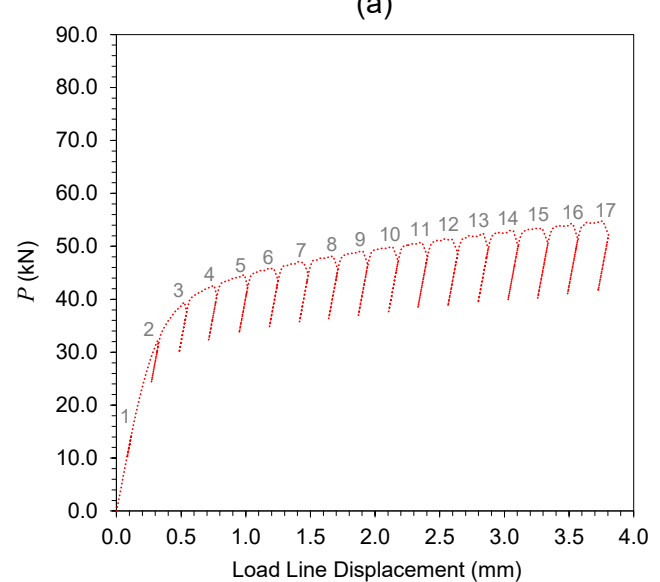

(b)

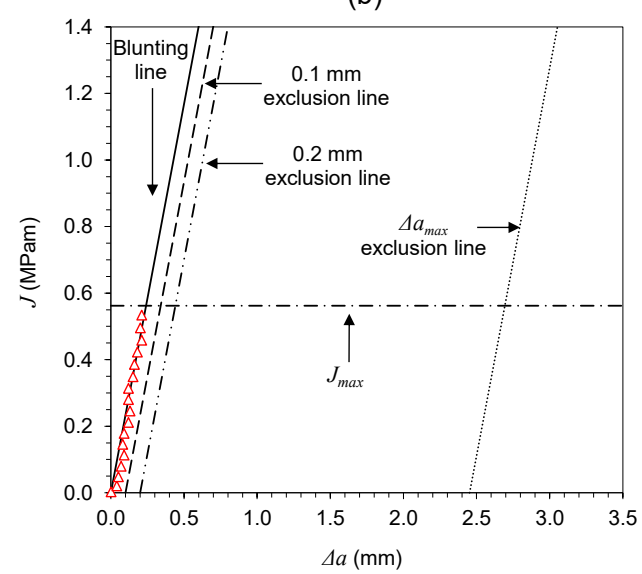

(c)

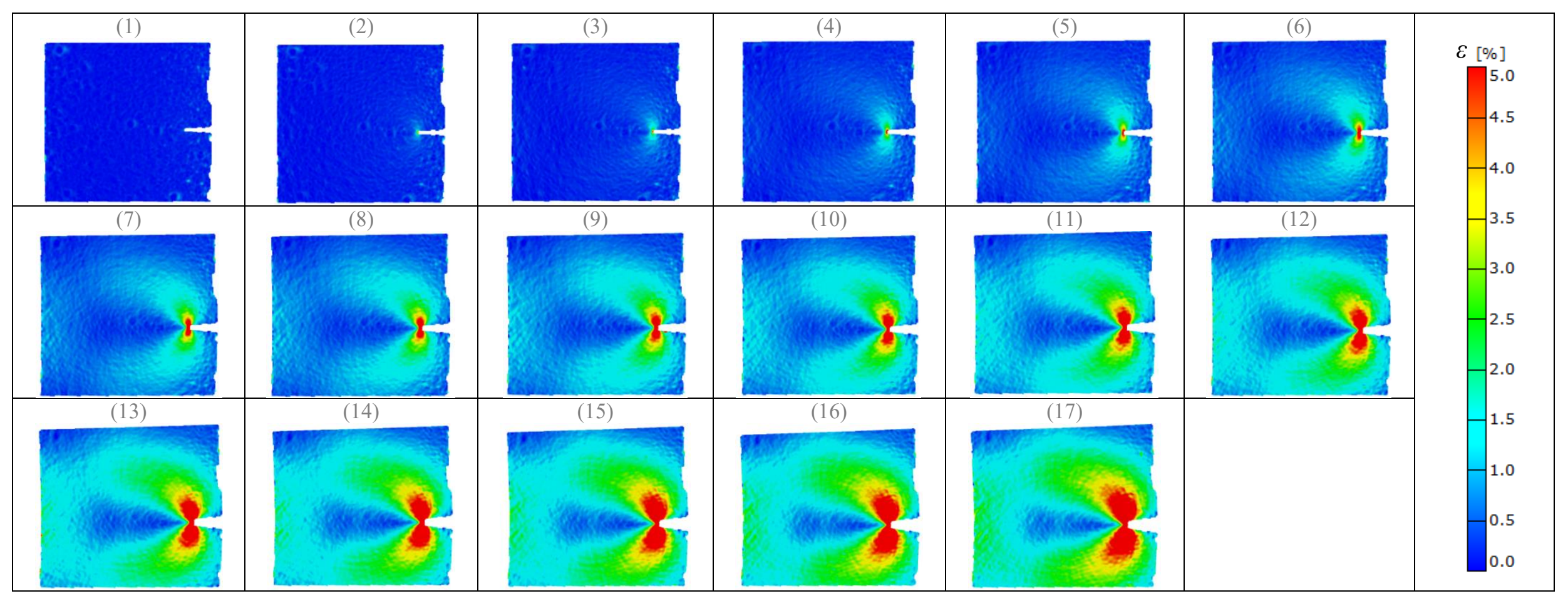

Figure 6: (a) Load vs. LLD data, (b) R-curve and (c) DIC strain distribution maps for JIC-AR-EDM specimen 
(a)

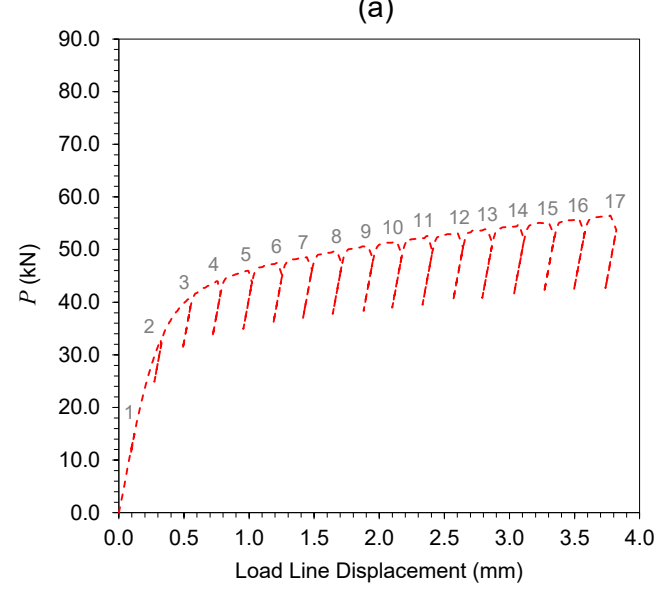

(c)
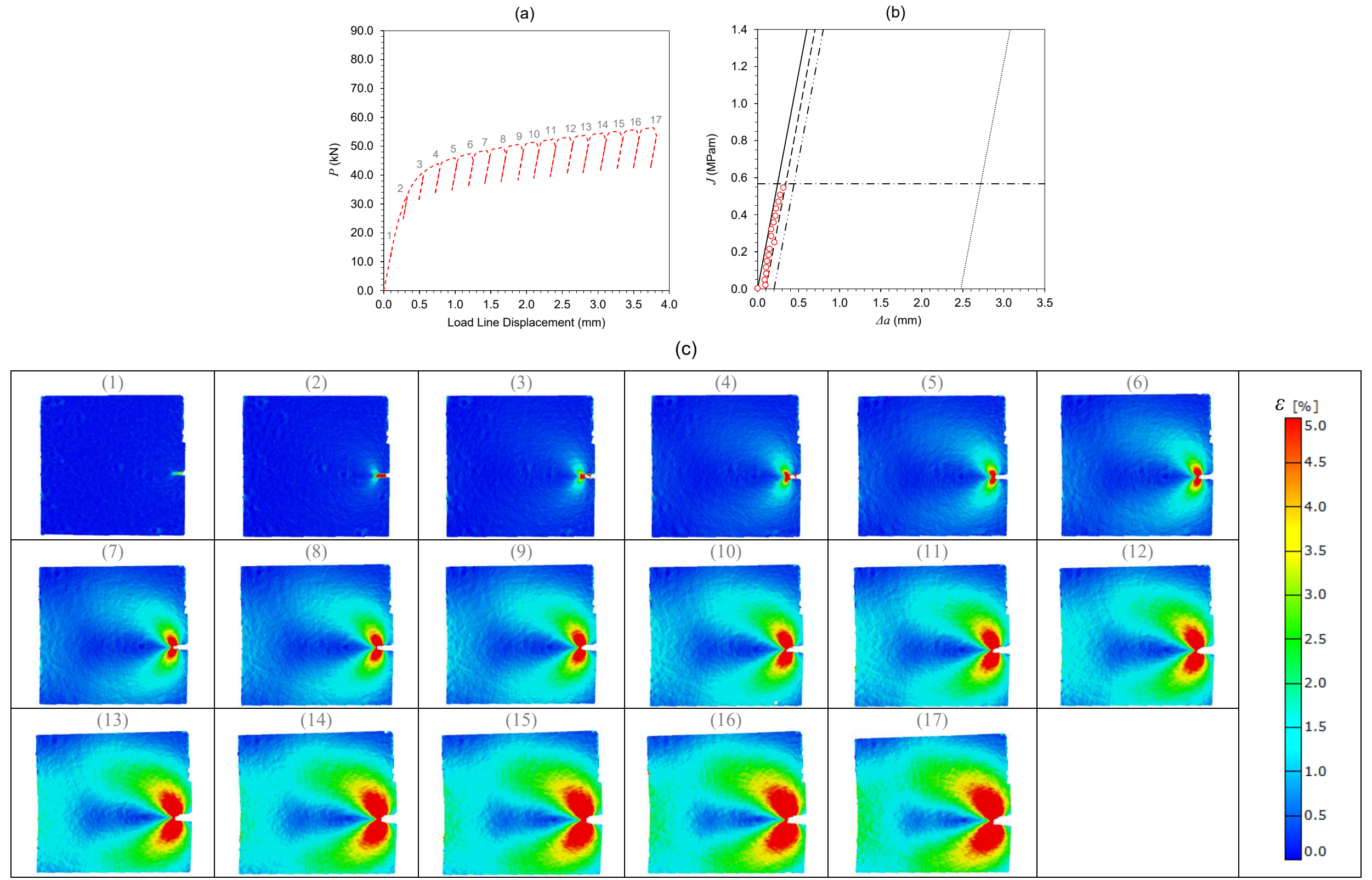

Figure 7: (a) Load vs. LLD data, (b) R-curve and (c) DIC strain distribution maps for JIC-AR-PF specimen 

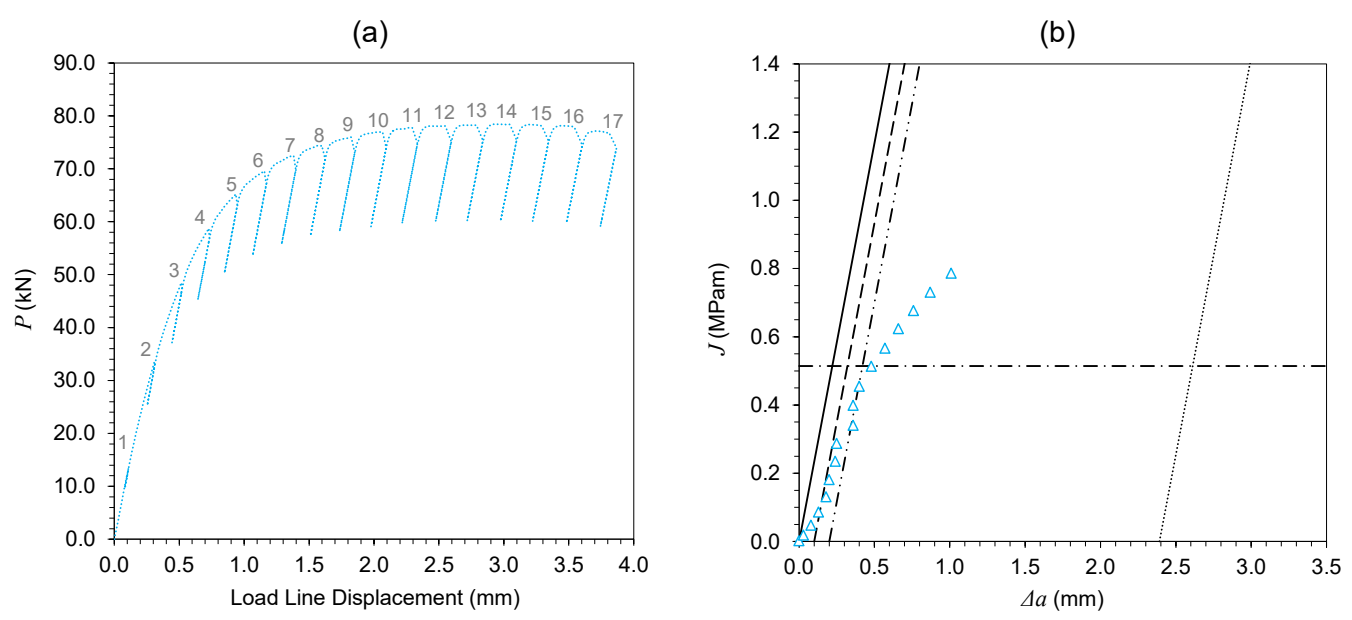

(c)

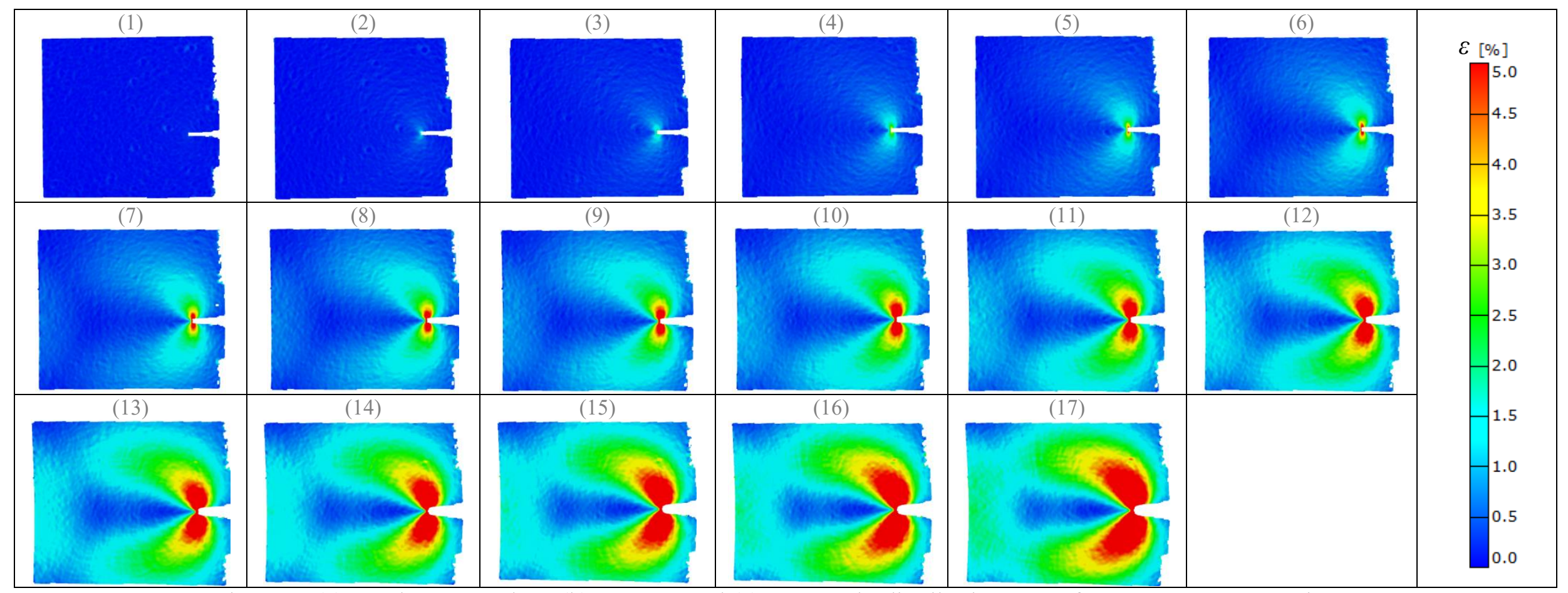

Figure 8: (a) Load vs. LLD data, (b) R-curve and (c) DIC strain distribution maps for JIC-PC-EDM specimen 
(a)

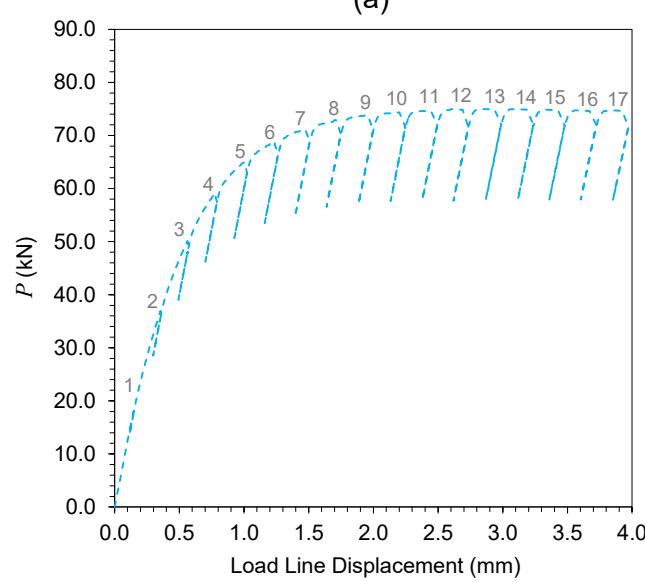

(b)

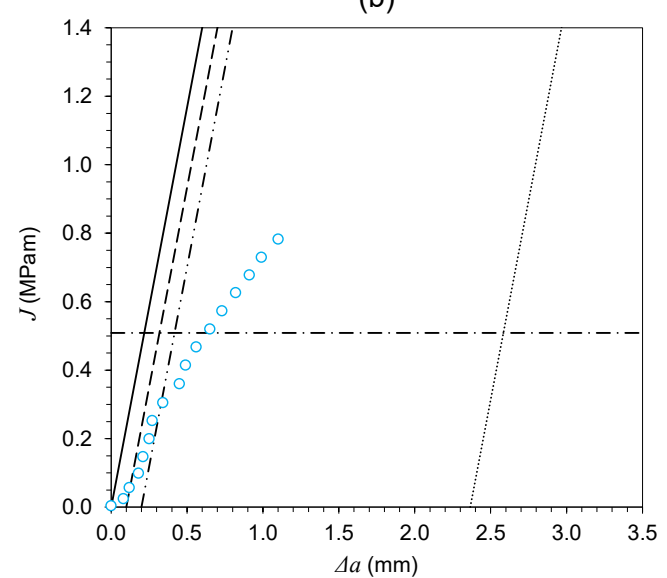

(c)

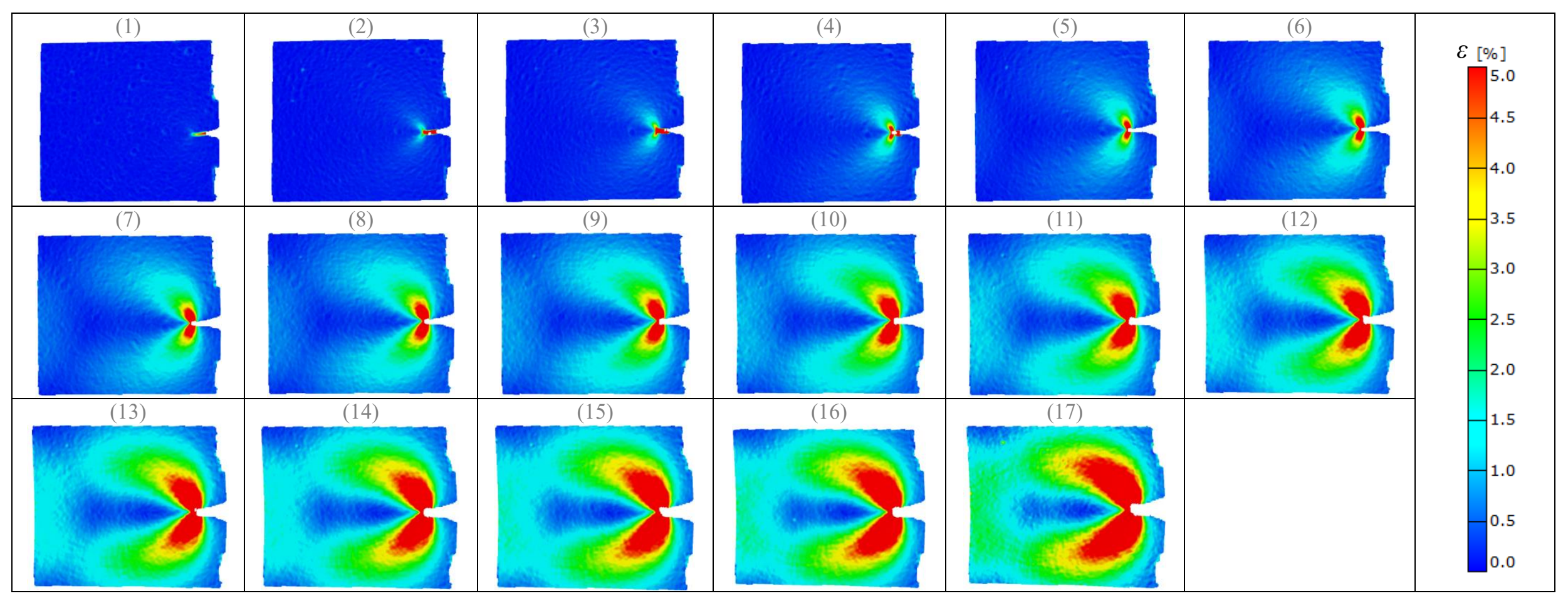

Figure 9: (a) Load vs. LLD data, (b) R-curve and (c) DIC strain distribution maps for JIC-PC-PF specimen 

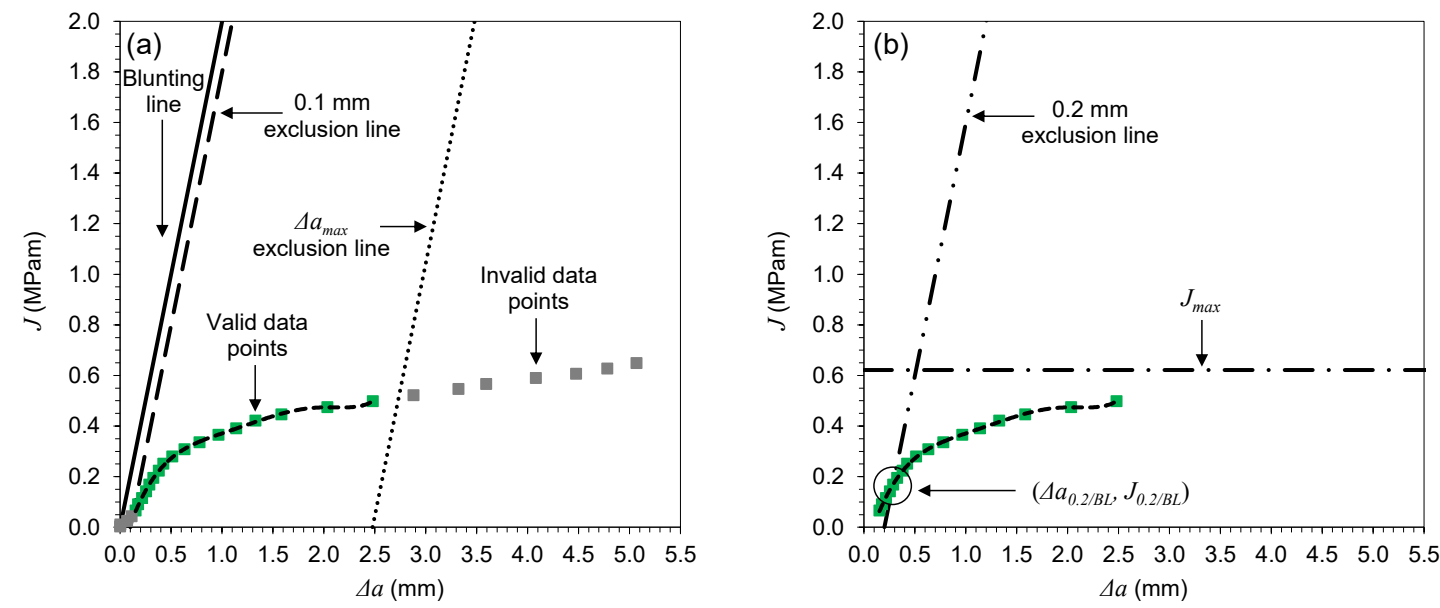

Figure 10: Fracture toughness data analysis for JIC-GCD-SG specimen (a) illustration of the exclusion lines (b) calculation of $J_{0.2 / B L}$

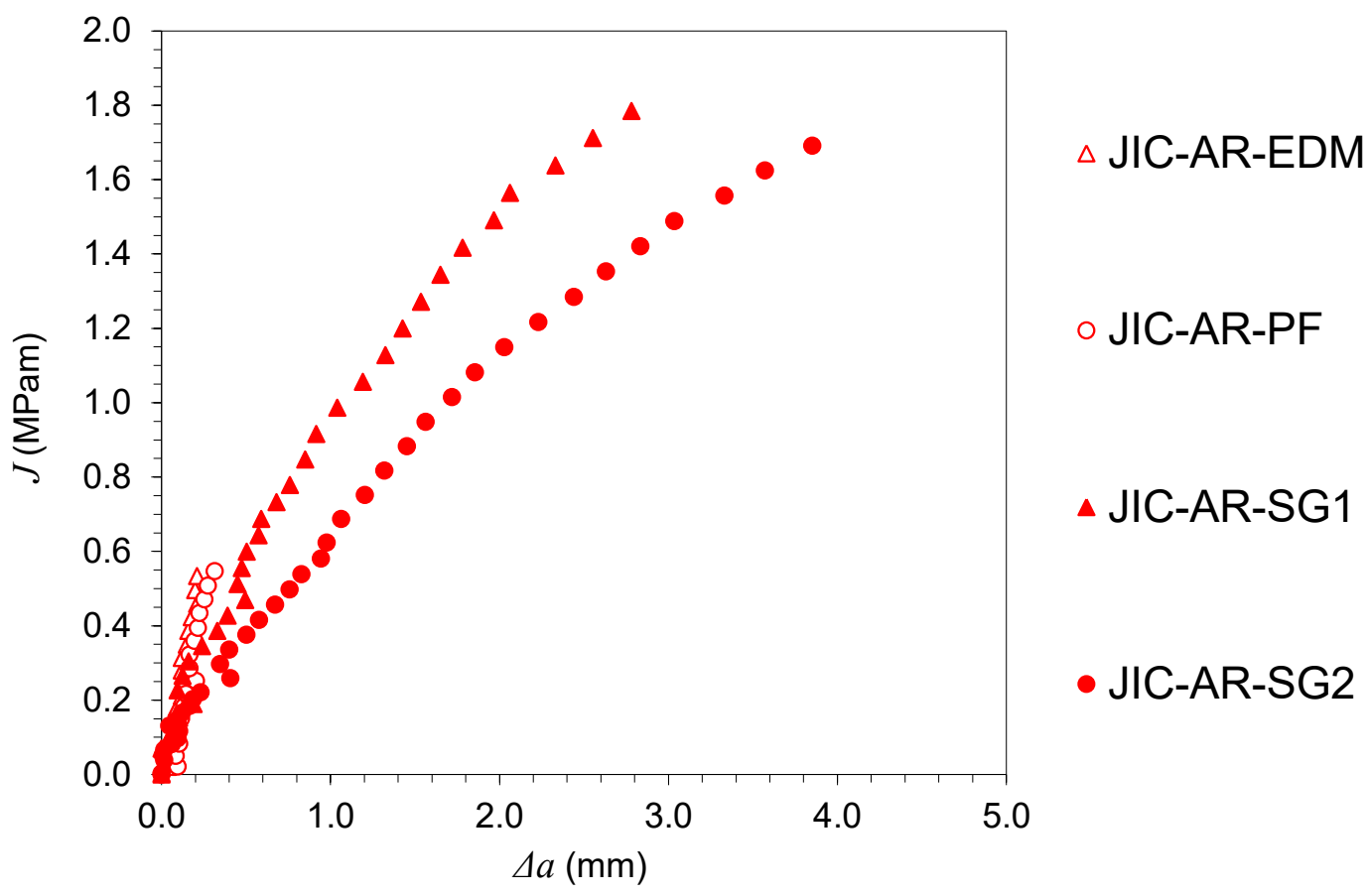

Figure 11: Comparison of the R-curves for the plain sided and side grooved AR specimens 


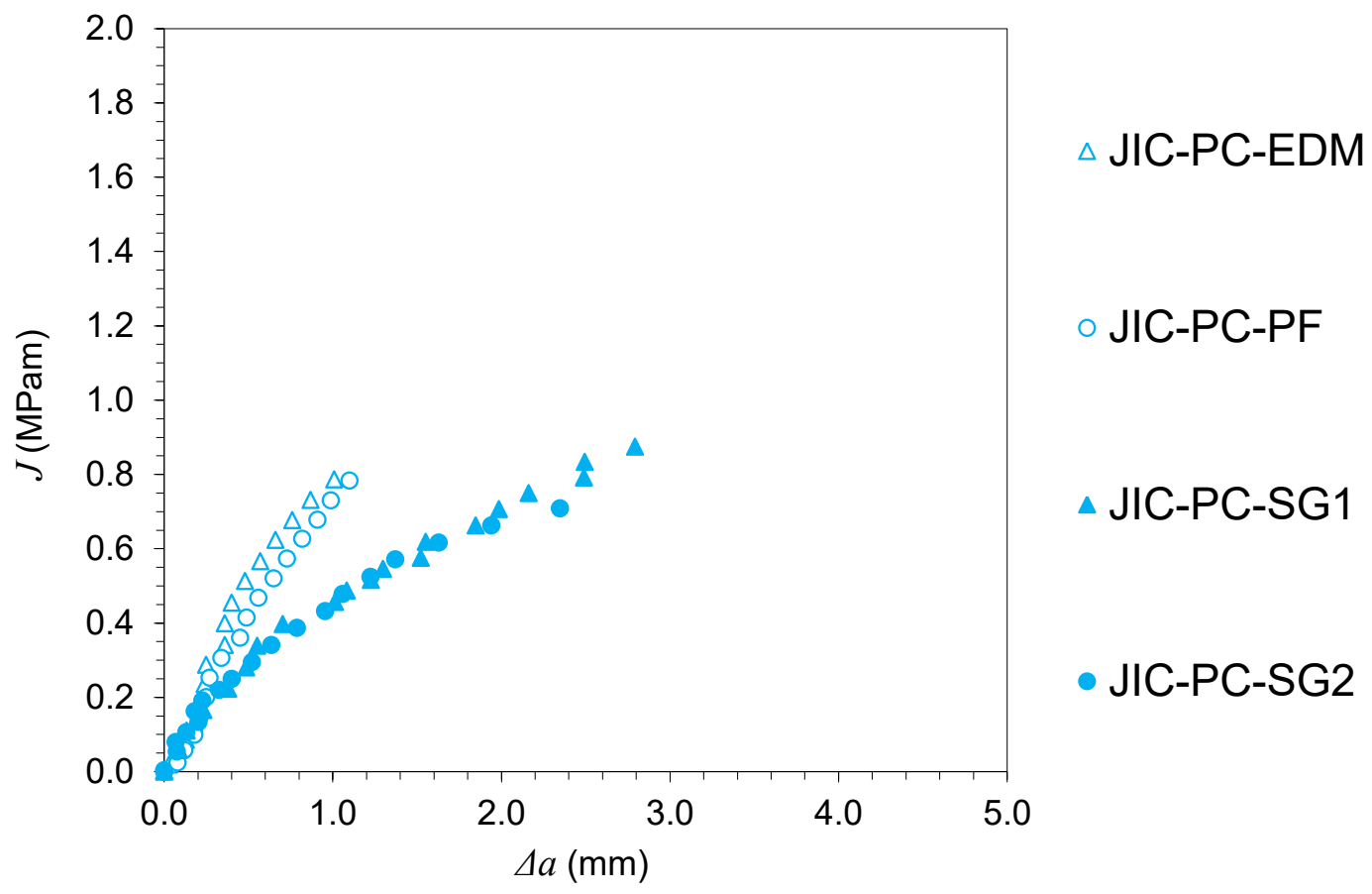

Figure 12: Comparison of the R-curves for the plain sided and side grooved PC specimens

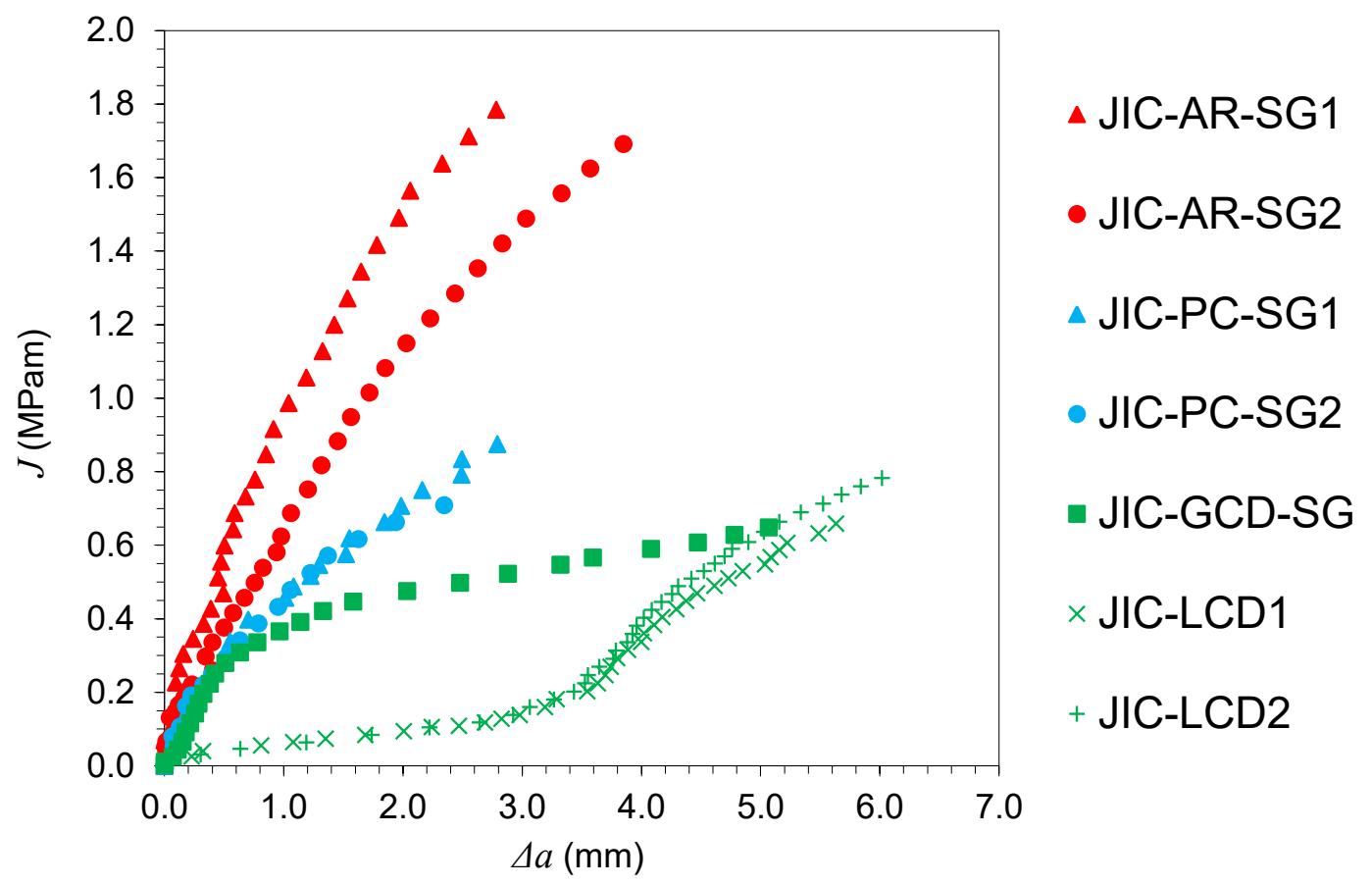

Figure 13: Comparison of the R-curves for the side grooved AR, PC, LCD and GCD specimens 